\title{
Effect of High-Intensity Interval Training on Plasma Omentin-1 Concentration in Overweight/Obese and Normal-Weight Youth
}

\author{
Nejmeddine Ouerghi ${ }^{a}$, b, c $\quad$ Mohamed Kacem Ben Fradj ${ }^{b} \quad$ Ikram Bezrati $^{b}$ \\ Moncef Feki $^{b}$ Naziha Kaabachib ${ }^{b}$ Anissa Bouassida ${ }^{a}$ \\ a Research Unit, Sportive Performance and Physical Rehabilitation, High Institute of \\ Sports and Physical Education of Kef, University of Jendouba, Kef, Tunisia; ${ }^{b}$ Laboratory of \\ Biochemistry, Rabta Hospital, Faculty of Medicine of Tunis, Tunis El Manar University, \\ Tunis, Tunisia; ' Faculty of Science of Bizerte, University of Carthage, Zarzouna, Tunisia
}

\section{Keywords}

Adipokines $\cdot$ Insulin resistance $\cdot$ Intermittent training $\cdot$ Omentin- $1 \cdot$ Physical performance

\begin{abstract}
Objectives: Omentin-1 is a recently discovered adipokine, mainly produced by visceral adipose tissue, which is thought to improve insulin sensitivity. The study aimed to assess the association of plasma omentin- 1 with cardiometabolic traits and physical performance and to test its response to high-intensity interval training (HIIT) in obese and normal-weight subjects. Methods: Nine overweight/obese (OG) and 9 normal-weight (NWG) young men performed an 8-week HIIT program. Body composition, physical performance, homeostasis model assessment index for insulin resistance (HOMA-IR) as well as plasma omentin-1and lipid levels were assessed before and after the HIIT program. Results: Baseline plasma omentin-1 was lower in OG than NWG men (359 \pm 138 vs. $470 \pm 114 \mathrm{ng} / \mathrm{ml} ; \mathrm{p}=0.052)$. Plasma omentin-1 was related to body fat $(r=-0.57 ; p=0.03)$ and LDL-cholesterol $(r=-0.49 ; p=$ 0.04). There was a trend towards significant association of omentin- 1 with BMI $(r=-0.47 ; p=$ $0.06)$ and VO2max $(r=0.41 ; p=0.09)$. However, no association was observed with HOMA-IR. Following the HIIT program, omentin-1 concentrations have significantly $(p<0.01)$ increased in OG (359 \pm 138 to $455 \pm 126 \mathrm{ng} / \mathrm{ml})$ and NWG men (470 \pm 114 to $572 \pm 115 \mathrm{ng} / \mathrm{ml})$. In parallel, the cardiometabolic profile has improved with a significant decrease of HOMA-IR in OG. Conclusions: HIIT resulted in a plasma omentin- 1 increase and an improvement with regard to cardiometabolic traits in the OG men, which may contribute to modulate insulin sensitivity.

(C) 2017 The Author(s)

Published by S. Karger $\mathrm{GmbH}$, Freiburg
\end{abstract}




\section{Introduction}

Obesity and fat excess have become major health problems worldwide. These conditions are associated with increased risk of metabolic dysfunctions such as type 2 diabetes mellitus and cardiovascular diseases [1]. Adipose tissue is an active endocrine organ that secretes various bioactive mediators, the so-called adipokines. These factors signal to several organs including liver, skeletal muscle, brain, and the immune system, modulating lipid and glucose metabolism as well as inflammation [2, 3]. Most adipokines are pro-inflammatory, whereas a small number is anti-inflammatory, exerting beneficial actions upon obesity and obesityassociated morbidities [3]. Omentin-1 is one of the recently discovered adipokines. It is mainly secreted by visceral adipose tissue and expressed in adipose tissue stromal vascular cells $[4,5]$. Omentin-1 was shown to enhance insulin-stimulated glucose transport and Akt phosphorylation in adipocytes, which suggest a role in improving insulin sensitivity [5]. Circulating omentin and omentin gene expression in adipose tissue are decreased in subjects with obesity, insulin resistance, or type 2 diabetes mellitus [6, 7]. Moreover, omentin levels were inversely related to BMI, waist circumference, insulin resistance and leptin, and positively related to adiponectin and HDL-cholesterol $[6,8]$. These data suggest that omentin plays a beneficial role in obesity and its co-morbidities. However, some recent prospective studies have linked omentin with increased risk of cardiovascular disease and type 2 diabetes [9-11].

Physical activity is an efficient strategy for fighting against obesity and promoting cardiometabolic health $[12,13]$. Physical exercise proved to modulate adipokine patterns $[14,15]$, which may contribute to its beneficial effect in obesity and obesity-related diseases. Data on the response of circulating omentin to physical training are rather scarce and inconsistent. Some studies showed increased levels $[16,17]$ while others showed no such variation $[18$, 19]. Almost all available data focused on omentin change following aerobic exercise training in middle-aged obese or diabetic individuals. The response of omentin to other types of training and among other groups of individuals remains unclear.

High-intensity interval training (HIIT) that alternates high-intensity periods of work and periods of rest has gained attention as time-efficient and effective method for improving cardiorespiratory fitness and reducing cardiometabolic risks [20, 21]. To date, only few studies examined the response of omentin to interval training in diabetic adults and individuals at high metabolic risk [22] as well as in middle-aged obese men [23]. This study aimed to test the response of plasma omentin to HIIT in overweight/obese and in normal-weight youth. It also examined the association of basal plasma omentin with cardiometabolic traits and physical performance indices. We hypothesized that HIIT modifies omentin level, along with improving cardiometabolic traits in young individuals, especially in those with weight excess.

\section{Material and Methods}

\section{Participants}

18 apparently healthy young males, selected among students of high class from two secondary schools in the city of Dahmani (Tunisia), volunteered for this study. Individuals with acute or chronic disease, those under medication, those consuming tobacco or alcohol, and trained athletes were excluded. A medical examination of each participant was done prior to inclusion revealing no contra-indications for physical exercise. Participants' habitual level of physical activity before/during the study consisted of $2 \mathrm{~h}$ of physical education lessons. Participants were divided based on BMI in a normal-weight group (NWG; BMI < $25 \mathrm{~kg} / \mathrm{m}^{2}$; age, 18.1 \pm 0.93 years; $n=9$ ) and an overweight/obese group (OG; BMI > $25 \mathrm{~kg} / \mathrm{m}^{2}$; age, $18.3 \pm 1.22$ years; $n=9$ ) . Participants followed a HIIT program, 3 times a week for 2 months. All participants conducted 24 training 
Table 1. Eight weeks of short HIIT program

\begin{tabular}{lllll}
\hline Week of training & $1-2$ & $3-4$ & $5-6$ & $7-8$ \\
\hline Number of series & 2 & 2 & 2 & 2 \\
Number of races per series & 8 & 10 & 10 & 10 \\
Run/active recuperation time, s & $30 / 30$ & $30 / 30$ & $30 / 30$ & $30 / 30$ \\
Percent of MAV (run/active recuperation) & $(100 / 50)$ & $(100 / 50)$ & $(105 / 50)$ & $(110 / 50)$ \\
Passive recovery time, min & 5 & 5 & 5 & 5 \\
Training load, ATU & 600 & 750 & 775 & 800
\end{tabular}

ATU $=$ Arbitrary training units.

Example: $(2 \times(8 \times 30 \mathrm{~s} / 30 \mathrm{~s}) ; 100 \% / 50 \% \mathrm{MAV}$; passive recovery time $=5 \mathrm{~min})$. It means that the subject had to run 2 series of 8 times $30 \mathrm{~s}$ : composed of 30 s running at $100 \%$ of MAV and $30 \mathrm{~s}$ active recovery at $50 \%$ of MAV. The subject recovers passively $5 \mathrm{~min}$ between each two series. Each session is repeated 3 times a week. Example of training load calculation for training sessions during the first week: $((100+50) / 2) \times 4$ $\times 2=600$ ATU.

sessions. Failure to attend one or more sessions was caught in the same or the following week. Participants were instructed to maintain their usual eating habits during the training program. The study was conducted in accordance with the guidelines of the Declaration of Helsinki and was approved by the Scientific and Ethics Committee of High Institute of Sports and Physical Education of Kef. Participants gave written informed consent to participate in the study.

\section{Study Protocol}

The study was conducted between February and April 2014. Temperature varied between 17 and $23{ }^{\circ} \mathrm{C}$ and humidity ranged from 70 to $75 \%$. Participants followed the HIIT program during 8 weeks. Body composition, physical performance, and metabolic profile were assessed 1 day before the start and 2 days after the last training session of the program.

Anthropometric Measurements

Weight and height were measured with the subjects barefoot and lightly clothed, allowing calculation of BMI $\left(\mathrm{kg} / \mathrm{m}^{2}\right)$ = weight $/$ height ${ }^{2}$. Skinfold thickness at four sites (biceps, triceps, sub-scapular and suprailiac sites) were monitored with Harperden's skinfold calipers (Baty International, West Sussex, UK). Percentage of body fat was assessed considering the skin-fold thickness at the four sites according to Durnin and Wormersley [24].

\section{Training Program}

The training program was designed for 8 weeks, 3 sessions per week (Monday, Wednesday and Friday). Each training session consisted of a 15-min warm-up, a main stage, and 10-min cool-down stage. Warm-up consisted of 10 -min continuous jogging at moderate intensity ( $50 \%$ of maximal aerobic velocity (MAV)), followed by 5 -min dynamic stretching exercises and 5 short bursts of 20 -meter accelerations. The main stage consisted of two series of 30-second runs at 100-110\% of MAV interspersed by periods of active recovery of 30 -second runs at $50 \%$ of MAV. Training progression was carried out by increasing the number of repetitions from 8 to 10 repetitions from the 3rd week, and increasing the intensity of work from the 5th week (5\% increase of the MAV every 2 weeks) (table 1). Finally, participants cooled down by running at low intensity and performing static stretching during $10 \mathrm{~min}$.

Physical Performance Tests

MAV and maximal oxygen uptake (VO2max) were measured via a continuous incremental field test, the Vameval Test [25]. The test was performed on a 400-meter outdoor running track. It starts at a running speed of $8 \mathrm{~km} / \mathrm{h}$ and increases by $0.5 \mathrm{~km} / \mathrm{h}$ every minute until exhaustion. Participants adjusted their running speed to cones placed at 20-meter intervals. The test ended when the subject could no longer maintain the required running speed dictated by an audio beep for 2 consecutive occasions. Heart rate was recorded during the test using a Polar heart rate monitor (Polar ${ }^{\mathrm{TM}}$ S810, Kempele, Finland). The highest value recorded 
during the Vameval test was considered to be the maximal heart rate (HRmax). To verify the accuracy of the MAV measurement, the HRmax was ensured to be within the interval theoretical HRmax \pm 10 .

Squat-jump (SJ) and counter movement jump (CMJ) were carried out as described by Bosco et al. [26], using an Optojump system (Globus; Microgate Ltd., Bolzano, Italy). The two tests differ by starting position, which is standing position for CMJ and $90^{\circ}$ of flexion of the knee joints for SJ. Participants are instructed to jump as high as possible while keeping their hands on their hips. Performance in SJ and CMJ was expressed in flight height $(\mathrm{cm})$. For each test, participants performed three trials with $1 \mathrm{~min}$ of recovery in between. The best performance was retained.

The five jump test (FJT) was carried out as described by Chamari et al. [27]. It consists of five successive horizontal jumps. The subject begins with joined feet and ends in the same position. Starting at right station, the subject performs five strides. He jumps on one leg (right or left) into raising the knee and the arms in front. During the 5 th stride, the subject brings back both legs together to go back to the starting position. Performance was expressed as total distance $(\mathrm{m})$.

Sprint tests were carried out as described by Chamari et al. [28]. Each subject was asked to run a distance of $30 \mathrm{~m}$ in a straight line as fast as possible with a free standing start. Three pairs of photocells were disposed in a straight line; the first one on the starting line, the second on the line of $10 \mathrm{~m}$ and the third on the finish line (30 m). The sprint time was registered with photoelectric cells (Microgate Ltd.) that were placed at $1 \mathrm{~m}$ height above ground. Each subject performed three trials in total with 3-min of recovery between efforts. The best performance was retained for the analysis.

Blood Sampling and Methods of Analysis

Fasting blood was sampled in morning (around 8 a.m.) from an antecubital vein into EDTA-containing tubes. The blood was drawn 1 day before the start and 2 days after the last training session. The samples were centrifuged at 2,000 $\times \mathrm{g}$ for $25 \mathrm{~min}$, and plasma was frozen at $-40{ }^{\circ} \mathrm{C}$ until analysis (within $3 \mathrm{months}$ ). Plasma omentin-1 was assessed using an enzymze-linked immunosorbent assay (ELISA) kit (BioVendor, Brno, Czech Republic) with an intra-assay CV below 5\%. Plasma insulin concentrations were measured by chemiluminescence immunoassay using a Liaison analyzer and the respective reagents kit (DiaSorin Inc., Stillwater, MN, USA). Plasma glucose, total cholesterol, HDL-cholesterol, and triglyceride were assessed by enzymatic colorimetric methods, and C-reactive protein by immuno-turbidimetric method using an Architect C8000 auto analyzer and the respective reagents kits (Abbott Laboratories, Abbott Park, IL, USA). LDLcholesterol was calculated using the Friedwald formula [29]. Insulin resistance was estimated by the homeostasis model assessment (HOMA-IR) index as HOMA-IR = (fasting insulin $(\mathrm{mU} / \mathrm{l}) \times$ fasting glucose $(\mathrm{mmol} / \mathrm{l})$ / 22.5)] [30].

\section{Statistical Analysis}

Statistical analysis was performed using the Statistical Package for the Social Sciences version 18.0 software (SPSS Inc., Chicago, IL, USA). Normality assumption of the data was confirmed using the KolmogorovSmirnov test and homogeneity of variance was verified using Levene's test. Independent-samples t-test was used to compare basal variables between groups (OG vs. NWG). Paired-samples t-test was used to compare pre-training and post-training variables in each group (OG or NWG). Changes in dependent variables resulting from the training program were assessed by two-way (time $\times$ group) repeated measures analysis of variance. Multiple regression models adjusting for group (OG/NWG) were applied to test correlations of baseline omentin with cardiometabolic traits and indices of physical performance. A p value $<0.05$ based on twosided calculation was considered significant.

\section{Results}

At inclusion, total cholesterol, LDL-cholesterol, triglycerides, C-reactive protein and insulin concentrations as well as HOMA-IR were significantly higher in the OG compared to the NWG, whereas aerobic and anaerobic parameters of physical performance were significantly better in NWG (table 2). There was a trend toward significant lower plasma omentin-1 concentrations in the OG compared to the NWG $(359 \pm 138 \mathrm{ng} / \mathrm{ml}$ vs. $470 \pm 114 \mathrm{ng} / \mathrm{ml} ; \mathrm{p}=$ 0.052). In regression models combining all participants and adjusting on groups, baseline 
Ouerghi et al.: Effect of High-Intensity Interval Training on Plasma Omentin-1

Concentration in Overweight/Obese and Normal-Weight Youth

Table 2. Anthropometric, physical performance and metabolic parameters at baseline (pre HIIT) and after (post HIIT) highintensity interval training in overweight/obese and normal-weight groups

\begin{tabular}{|c|c|c|c|c|c|c|}
\hline & \multicolumn{2}{|l|}{ NWG (n = 9) } & \multicolumn{2}{|l|}{$O G(n=9)$} & \multicolumn{2}{|c|}{$\begin{array}{l}\text { Interaction } \\
(\text { time } \times \text { group })^{a}\end{array}$} \\
\hline & pre HIIT & post HIIT & pre HIIT & post HIIT & $\mathrm{F}$ & $\mathrm{P}$ \\
\hline BMI, $\mathrm{kg} / \mathrm{m}^{2}$ & $20.5 \pm 1.51$ & $20.5 \pm 1.67$ & $30.8 \pm 4.56^{* * *}$ & $30.3 \pm 4.25^{\dagger}$ & 6.24 & 0.024 \\
\hline Body fat, $\%$ & $12.0 \pm 3.28$ & $11.9 \pm 3.10$ & $22.5 \pm 1.87^{* * *}$ & $22.1 \pm 1.82^{\dagger}$ & 2.17 & 0.160 \\
\hline $\mathrm{MAV}, \mathrm{km} / \mathrm{h}$ & $14.9 \pm 0.53$ & $15.4 \pm 0.74^{\dagger \dagger}$ & $11.5 \pm 1.15^{* * *}$ & $12.1 \pm 0.96^{\dagger \dagger}$ & 0.64 & 0.434 \\
\hline $\mathrm{VO} 2 \mathrm{max}, \mathrm{ml} / \mathrm{kg} / \mathrm{min}$ & $54.1 \pm 1.84$ & $55.6 \pm 2.58^{\dagger \dagger}$ & $42.0 \pm 4.03^{* * *}$ & $44.2 \pm 3.37^{+\dagger}$ & 0.58 & 0.459 \\
\hline Heart rate max, beat/min & $190 \pm 10.0$ & $189 \pm 10.2$ & $193 \pm 8.65$ & $192 \pm 7.58$ & 0.03 & 0.859 \\
\hline 10-meter sprint time, s & $2.01 \pm 0.11$ & $2.01 \pm 0.14$ & $2.40 \pm 0.17^{* * *}$ & $2.37 \pm 0.15^{\dagger}$ & 1.13 & 0.304 \\
\hline 30-meter sprint time, s & $4.62 \pm 0.19$ & $4.59 \pm 0.20^{\dagger}$ & $5.63 \pm 0.47^{* * *}$ & $5.58 \pm 0.43^{\dagger}$ & 0.30 & 0.591 \\
\hline Squat jump height, $\mathrm{cm}$ & $28.2 \pm 2.77$ & $30.0 \pm 2.71^{\dagger+}$ & $19.8 \pm 4.18^{* * *}$ & $20.8 \pm 4.21^{\dagger \dagger}$ & 2.31 & 0.148 \\
\hline CMJ height, $\mathrm{cm}$ & $30.0 \pm 3.24$ & $32.0 \pm 3.43^{+\dagger}$ & $21.6 \pm 4.92^{* * *}$ & $23.0 \pm 5.11^{\dagger \dagger}$ & 0.74 & 0.404 \\
\hline Five jump test length, m & $11.1 \pm 0.53$ & $11.4 \pm 0.69^{+\dagger}$ & $8.99 \pm 1.18^{* * *}$ & $9.30 \pm 1.15^{+\dagger}$ & 0.01 & 0.910 \\
\hline Cholesterol, mg/dl & $136 \pm 20.3$ & $127 \pm 20.2$ & $175 \pm 26.0^{* *}$ & $150 \pm 15.8^{\dagger}$ & 2.39 & 0.142 \\
\hline Triglycerides, mg/dl & $82.5 \pm 31.1$ & $68.4 \pm 16.5$ & $122 \pm 39.0^{*}$ & $90.0 \pm 21.2^{\dagger}$ & 1.25 & 0.280 \\
\hline LDL-cholesterol, mg/dl & $85.2 \pm 19.2$ & $79.2 \pm 15.4$ & $113 \pm 30.0^{*}$ & $96.2 \pm 13.1^{\dagger}$ & 1.62 & 0.221 \\
\hline HDL-cholesterol, mg/dl & $36.3 \pm 6.15$ & $36.4 \pm 7.23$ & $37.0 \pm 2.12$ & $37.2 \pm 3.21$ & 0.09 & 0.764 \\
\hline Fasting glucose, mg/dl & $89.8 \pm 10.5$ & $91.1 \pm 9.98$ & $100 \pm 13.9$ & $93.9 \pm 7.83$ & 1.10 & 0.309 \\
\hline Fasting insulin, $\mu \mathrm{IU} / \mathrm{ml}$ & $8.18 \pm 5.04$ & $5.69 \pm 3.39$ & $21.3 \pm 14.22^{* *}$ & $13.4 \pm 5.88$ & 1.19 & 0.292 \\
\hline HOMA-IR & $1.87 \pm 1.43$ & $1.26 \pm 0.51$ & $4.99 \pm 2.62^{* *}$ & $3.12 \pm 1.47^{\dagger}$ & 1.96 & 0.181 \\
\hline C-reactive protein, mg/l & $0.85 \pm 0.67$ & $1.26 \pm 1.42$ & $2.78 \pm 1.58^{* *}$ & $2.97 \pm 1.78$ & 0.10 & 0.759 \\
\hline
\end{tabular}

Data are expressed as mean \pm SD.

${ }^{*} \mathrm{p}<0.05 ;{ }^{* *} \mathrm{p}<0.01 ;{ }^{* * *} \mathrm{p}<0.001$ (compared to baseline in normal-weight group); ${ }^{\dagger} \mathrm{p}<0.05 ;{ }^{\dagger \dagger} \mathrm{p}<0.01$ (compared to baseline in the same group).

${ }^{\mathrm{a} C o m p a r i s o n}$ was performed using two-way repeated measures ANOVA.

plasma omentin-1 was inversely related to body fat and LDL-cholesterol. There was trend towards significant correlations of omentin-1 with BMI, total cholesterol, and VO2max (fig. 1). No significant correlations were observed with HOMA-IR, C-reactive protein, or the indices of anaerobic physical performance.

Eight weeks of HIIT program resulted in a significant increase in plasma omentin- 1 in both the OG and NWG (fig. 2). BMI and body fat have decreased in the OG, but not in the NWG. Following the training program, the indices of physical performance (MAV, VO2max, FJT, SJ, $\mathrm{CMJ}$, and 30-meter sprint time) have significantly improved in both groups while the 10-meter sprint time has improved in OG only. Finally, total cholesterol, LDL-cholesterol, triglycerides, and HOMA-IR have significantly decreased in OG, only. Repeated measures detected a significant difference between OG and NWG for BMI, only. No significant differences were detected for all other variables (table 2).

\section{Discussion}

The main finding of the study was an increase in plasma omentin levels following HIIT in both overweight/obese and normal-weight untrained young men. Baseline plasma omentin tended towards being significantly lower in the OG compared to the NWG. The last finding agrees with literature data of decreased omentin levels in overweight, obese and diabetic subjects $[6,7,18]$. Plasma omentin was negatively related to body fat and LDL-cholesterol. These findings agree with data from cross-sectional analyses $[6,8,16]$ suggesting a beneficial 


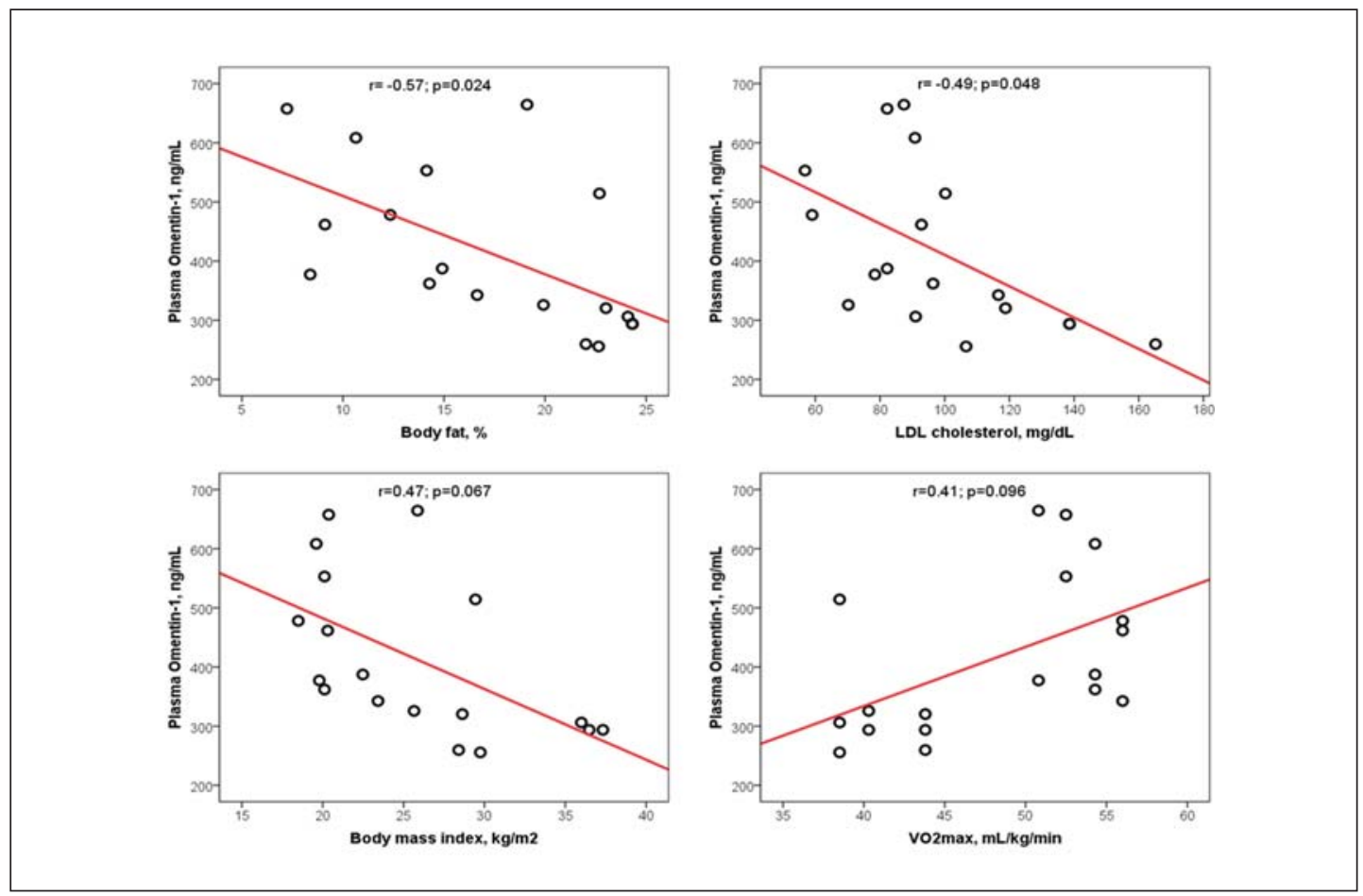

Fig. 1. Correlation of baseline omentin-1 with selected cardiometabolic traits and indices of physical performance.

Fig. 2. Plasma omentin-1 concentration in overweight/obese and normal-weight young men at baseline and after HIIT program. ${ }^{* *} \mathrm{p}<0.01$ (compared to baseline in the same group); ${ }^{\dagger} \mathrm{p}=0.052$ (compared to NWG).

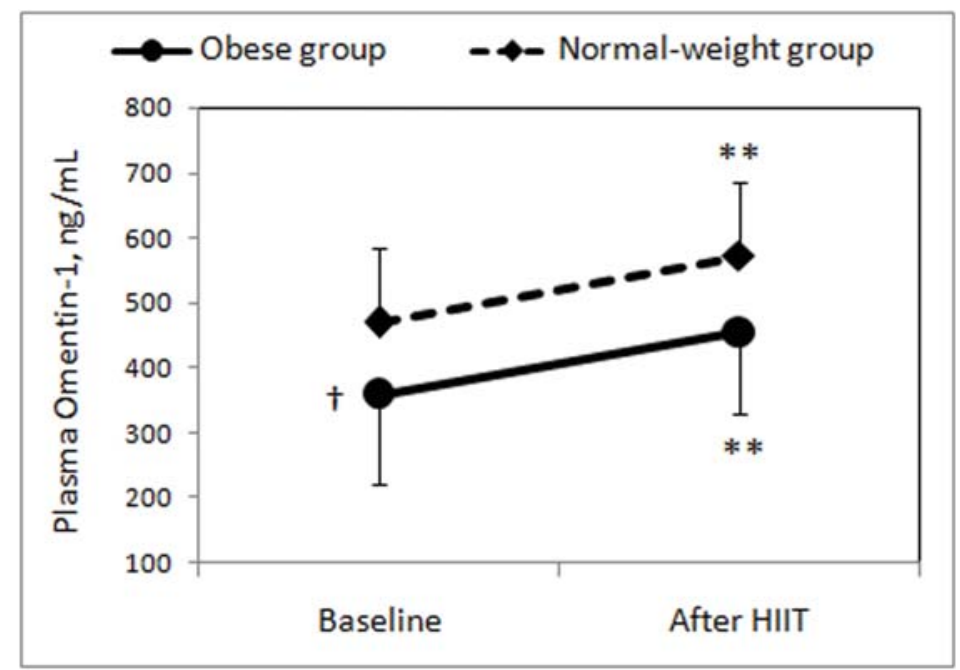

role of omentin in cardiometabolic health. However, there is prospective evidence linking omentin with increased risk of type 2 diabetes and cardiovascular disease [9-11]. The present study found no associations between circulating omentin and HOMA-IR or C-reactive protein. Such data could be part of the controversy over the role of this adipokine in cardiometabolic health. Further work is necessary to examine the role of omentin in cardiometabolic health and to elucidate the underlying mechanisms.

In accordance with previous reports $[16,17]$, this study showed circulating omentin to be related to VO2max. Such an association is understandable as both circulating omentin and 
physical fitness are actually low in overweight/obese subjects compared to normal-weight subjects. The study detected no significant relationship between circulating omentin and indices of anaerobic performance. To date, no data are available on the association between omentin and anaerobic performance.

Following HIIT, plasma omentin had increased in both overweight/obese and healthy normal-weight youth. In accordance, Madsen et al. [21, 22] reported that an 8-week HIIT training (strenuous bicycle exercise) had induced improvement in circulating omentin, together with abdominal fat mass loss and enhanced glycemic control in middle-aged type 2 diabetics. However, Nikseresht et al. [23] showed no change in omentin after 12 weeks of moderate interval training in middle-aged obese men. The response to aerobic training also showed mixed results, with studies showing omentin increase $[16,17]$ and others showing no change $[18,19]$. The present research is the first to document omentin increase after interval training in youth as well as in normal-weight individuals.

In parallel with omentin increase, the training resulted in improvement in fatness, plasma lipids, and insulin sensitivity in the obese. Previous studies showed concomitant improvement of omentin and cardiometabolic traits following endurance training [16] or dietary intervention [31]. Hence, it could be supposed that omentin increases as a consequence of weight loss or improvement of obesity-related factors. However, circulating omentin had also increased following physical training in obese women with no parallel change in body weight or metabolic traits [17]. Conversely, omentin remained unchanged after exercise training despite significant reductions in weight, insulin, and HOMA-IR [18]. Thus, exercise-associated omentin change could not fully be attributed to weight loss. It may increase in response to physiological adaptation of skeletal muscle to exercise. Skeletal muscle releases myokines into the systemic circulation in response to exercise [32]. These myokines act on various tissues including the adipose tissue, influencing glucose and lipid metabolisms, and energy balance [32]. For instance, circulating irisin had increased following high-intensity interval exercise [33]. Wilms et al. [17] hypothesized that exercise-induced release of myokines from the muscle fibers may modulate omentin secretion by adipose tissue. However, circulating omentin did not change after physical training $[18,19]$, and increased following dietary intervention [31]. So, it is not clear whether omentin increases as a result of the training itself or as a consequence of the improvement of body composition.

The present study has some limitations. The group sizes are small, and a control group without training is lacking. This may make the finding less consistent and especially makes it difficult to establish causal relationship between plasma omentin increase and improvement of cardiometabolic traits. The study did not control for dietary intake and energy expenditure, which could affect adipose tissue homeostasis. Finally, body fat was estimated based on the skinfold thickness method, which is not as accurate as DEXA scan or MRI for this purpose.

In conclusion, the study showed that omentin is associated with body composition and cholesterol, but not with indices of insulin sensitivity and inflammation. Interval training resulted in an increase in circulating omentin, which was concomitant with an improvement of cardiometabolic traits in the obese. The role of omentin in cardiometabolic health is still not well understood. Further research is needed to clarify the mechanisms of omentin change upon physical training, as well as its impact on physical performance and cardiometabolic health.

\section{Acknowledgments}

The study was supported by Funds of UR13JS01 (Ministry of Youth and Sports of Tunisia) and LR99ES11 (Ministry of Higher Education and Scientific Research of Tunisia). The authors are grateful to the participants for their valuable contribution to achieve the training program and for their kindness and courage. 


\section{Disclosure Statement}

The authors declare that there are no conflicts of interest.

\section{References}

1 Matsuzawa Y, Funahashi T, Nakamura T: The concept of metabolic syndrome: contribution of visceral fat accumulation and its molecular mechanism. J Atheroscler Thromb 2011;18:629-639.

2 Ouchi N, Parker JL, Lugus JJ, Walsh K: Adipokines in inflammation and metabolic disease. Nat Rev Immunol 2011;11:85-97.

3 Ohashi K, Shibata R, Murohara T, Ouchi N: Role of anti-inflammatory adipokines in obesity-related diseases. Trends Endocrinol Metab 2014;25:348-355.

4 Schäffler A, Neumeier M, Herfarth H, Fürst A, Schölmerich J, Büchler C: Genomic structure of human omentin, a new adipocytokine expressed in omental adipose tissue. Biochim Biophys Acta 2005;1732:96-102.

5 Yang RZ, Lee MJ, Hu H, Pray J, Wu HB, Hansen BC, Shuldiner AR, Fried SK, McLenithan JC, Gong DW: Identification of omentin as a novel depot-specific adipokine in human adipose tissue: possible role in modulating insulin action. Am J Physiol Endocrinol Metab 2006;290:E1253-E1261.

6 de Souza Batista CM, Yang RZ, Lee MJ, Glynn NM, Yu DZ, Pray J, Ndubuizu K, Patil S, Schwartz A, Kligman M, Fried SK, Gong DW, Shuldiner AR, Pollin TI, McLenithan JC: Omentin plasma levels and gene expression are decreased in obesity. Diabetes 2007;56:1655-1661.

7 Zhang Q, Zhu L, Zheng M, Fan C, Li Y, Zhang D, He Y, Yang H: Changes of serum omentin-1 levels in normal subjects, type 2 diabetes and type 2 diabetes with overweight and obesity in Chinese adults. Ann Endocrinol (Paris) 2014; 75:171-175.

8 Tan BK, Pua S, Syed F, Lewandowski KC, O’Hare JP, Randeva HS: Decreased plasma omentin-1 levels in type 1 diabetes mellitus. Diabet Med 2008;25:1254-1255.

9 Saely CH, Leiherer A, Muendlein A, Vonbank A, Rein P, Geiger K, Malin C, Drexel H: Coronary patients with high plasma omentin are at a higher cardiovascular risk. Data Brief 2015;6:158-161.

10 Menzel J, di Giuseppe R, Biemann R, Wittenbecher C, Aleksandrova K, Pischon T, Fritsche A, Schulze MB, Boeing $\mathrm{H}$, Isermann B, Weikert C: Omentin-1 and risk of myocardial infarction and stroke: results from the EPICPotsdam cohort study. Atherosclerosis 2016;251:415-421.

11 Wittenbecher C, Menzel J, Carstensen-Kirberg M, Biemann R, di Giuseppe R, Fritsche A, Isermann B, Herder C, Aleksandrova K, Boeing H, Weikert C, Schulze MB. Omentin-1, adiponectin, and the risk of developing type 2 diabetes. Diabetes Care 2016;39:e79-80.

12 Anderssen SA, Carroll S, Urdal P, Holme I: Combined diet and exercise intervention reverses the metabolic syndrome in middle-aged males: results from the Oslo Diet and Exercise Study. Scand J Med Sci Sports 2007; 17:687-695.

13 Haskell WL, Lee IM, Pate RR, Powell KE, Blair SN, Franklin BA, Macera CA, Heath GW, Thompson PD, Bauman A: Physical activity and public health: updated recommendation for adults from the American College of Sports Medicine and the American Heart Association. Med Sci Sports Exerc 2007;39:1423-1434.

14 Bouassida A, Chamari K, Zaouali M, Feki Y, Zbidi A, Tabka Z: Review on leptin and adiponectin responses and adaptations to acute and chronic exercise. Br J Sports Med 2010;44:620-630.

15 Kadoglou NP, Vrabas IS, Kapelouzou A, Angelopoulou N: The association of physical activity with novel adipokines in patients with type 2 diabetes. Eur J Intern Med 2012;23:137-142.

16 Saremi A, Asghari M, Ghorbani A: Effects of aerobic training on serum omentin-1 and cardiometabolic risk factors in overweight and obese men. J Sports Sci 2010;28:993-998.

17 Wilms B, Ernst B, Gerig R, Schultes B: Plasma omentin-1 levels are related to exercise performance in obese women and increase upon aerobic endurance training. Exp Clin Endocrinol Diabetes 2015;123:187-192.

18 Urbanová M, Dostálová I, Trachta P, Drápalová J, Kaválková P, Haluzíková D, Matoulek M, Lacinová Z, Mráz M, Kasalický M, Haluzík M: Serum concentrations and subcutaneous adipose tissue mRNA expression of omentin in morbid obesity and type 2 diabetes mellitus: the effect of very-low-calorie diet, physical activity and laparoscopic sleeve gastrectomy. Physiol Res 2014;63:207-218.

19 Faramarzi M, Banitalebi E, Nori S, Farzin S, Taghavian Z: Effects of rhythmic aerobic exercise plus core stability training on serum omentin, chemerin and vaspin levels and insulin resistance of overweight women. J Sports Med Phys Fitness 2016;56:476-482.

20 Weston KS, Wisløff U, Coombes JS: High-intensity interval training in patients with lifestyle-induced cardiometabolic disease: a systematic review and meta-analysis. Br J Sports Med 2014;48:1227-1234.

21 Madsen SM, Thorup AC, Overgaard K, Jeppesen PB: High intensity interval training improves glycaemic control and pancreatic $\beta$ cell function of type 2 diabetes patients. PLoS One 2015;10:e0133286.

22 Madsen SM, Thorup AC, Bjerre M, Jeppesen PB: Does 8 weeks of strenuous bicycle exercise improve diabetesrelated inflammatory cytokines and free fatty acids in type 2 diabetes patients and individuals at high-risk of metabolic syndrome? Arch Physiol Biochem 2015;121:129-138. 
Ouerghi et al.: Effect of High-Intensity Interval Training on Plasma Omentin-1

Concentration in Overweight/Obese and Normal-Weight Youth

23 Nikseresht M, Hafezi Ahmadi MR, Hedayati M: Detraining-induced alterations in adipokines and cardiometabolic risk factors after nonlinear periodized resistance and aerobic interval training in obese men. Appl Physiol Nutr Metab 2016;27:1-8.

24 Durnin JV, Womersley J: Body fat assessed from total body density and its estimation from skinfold thickness: measurements on 481 men and women aged from 16 to 72 years. Br J Nutr 1974;32:77-97.

25 Cazorla G: Field tests to evaluate aerobic capacity and maximal aerobic speed. Proc Int Symposium Guadeloupe, 1990, pp 151-173.

26 Bosco C, Luhtanen P, Komi PV: A simple method for measurement of mechanical power in jumping. Eur J Appl Physiol Occup Physiol 1983;50:273-282.

27 Chamari K, Chaouachi A, Hambli M, Kaouech F, Wisløff U, Castagna C: The five-jump test for distance as a field test to assess lower limb explosive power in soccer players. J Strength Cond Res 2008;22:944-950.

28 Chamari K, Hachana Y, Ahmed YB, Galy O, Sghaïer F, Chatard JC, Hue O, Wisløff U: Field and laboratory testing in young elite soccer players. Br J Sports Med 2004;38:191-196.

29 Friedewald WT, Levy RI, Fredrickson DS: Estimation of the concentration of low-density lipoprotein cholesterol in plasma, without use of the preparative ultracentrifuge. Clin Chem 1972;18:499-502.

30 Matthews DR, Hosker JP, Rudenski AS, Naylor BA, Treacher DF, Turner RC: Homeostasis model assessment: insulin resistance and beta-cell function from fasting plasma glucose and insulin concentrations in man. Diabetologia 1985;28:412-419.

31 Moreno-Navarrete JM, Ortega F, Castro A, Sabater M, Ricart W, Fernández-Real JM: Circulating omentin as a novel biomarker of endothelial dysfunction. Obesity (Silver Spring) 2011;19:1552-1559.

32 Pedersen L, Hojman P: Muscle-to-organ cross talk mediated by myokines. Adipocyte 2012;1:164-167.

33 Huh JY, Mougios V, Kabasakalis A, Fatouros I, Siopi A, Douroudos II, Filippaios A, Panagiotou G, Park KH, Mantzoros CS: Exercise-induced irisin secretion is independent of age or fitness level and increased irisin may directly modulate muscle metabolism through AMPK activation. J Clin Endocrinol Metab 2014;99:E2154E2161. 